\title{
ANALISIS TATA LETAK FASILITAS DENGAN MENGGUNAKAN METODE ACTIVITY RELATIONSHIP CHART PADA INDUSTRI MEBEL BAMBU KARYA MANUNGGAL YOGYAKARTA
}

\author{
Marni Astuti, Eko Poerwanto, Agus Trianingsih \\ Prodi Teknik Industri Sekolah Tinggi Teknologi Adisutjipto Yogyakarta \\ Jl. Janti, Blok R, Lanud Adisutjipto Yogyakarta \\ E-mail: ${ }^{1}$ stta_marni@yahoo.co.id
}

\begin{abstract}
Plant layout or facilities layout is to fix regulate facilities layout with consider material handling flow. In this research on Bamboo Furniture Industry Karya Manunggal Yogyakarta show less precisely placement of production facilities and flow material resulting in the total distances of material handling becomes long and induce the total cost of material handling becomes high. Improvement of facilities layout performed with qualitative methods ARC (Activity Relationship Chart). This matter do for obtain a new layout with minimum total distances of material handling and minimum total cost of material handling. In this research use POM QM Software for validating total distances of material handling. Analysis result and designing facilities layout is a new layout with Rectilinear Distance method, The initial movement distances is $1.922,9 \mathrm{~m}$ become $1.832,35 \mathrm{~m}$ or have a reduction distances $4,94 \%$ from initial layout. While for the initial total cost of material handling is Rp 200.135,6 become Rp 199.745,9 or have a reduction cost 0,19\% from initial layout. Existence a new layout based on $A R C$ be expected on the production floor of Bamboo Furniture Industry Karya Manunggal Yogyakarta.
\end{abstract}

Keyword : Layout, Qualitative Method (ARC), Rectilinear Distance, Distance of material handling, Cost of material handling

1. Pendahuluan

Suatu industri dapat mencapai tujuan pencapaian produksi yang optimal menerapkan pengendalian mutu pada proses produksinya. Salah satu hal yang diperhatikan dalam merencanakan site layout yang optimal, adalah mengatur tata letak site facility [1]. Tata letak fasilitas yang baik akan menghasilkan aliran proses yang lancar saat produksi sehingga produktivitas perusahaan menjadi maksimum dan meminimumkan biaya produksi.

Permasalahan tata letak yang terdapat pada Industri Mebel Bambu Karya Manunggal adalah tata letak yang dapat berubah sewaktu-waktu. Tata letak yang dapat berubah disebabkan oleh ukuran produk yang akan di produksi serta hal ini dikarenakan tata letak yang diterapkan sesuai dengan keinginan dari pekerja. Tidak hanya itu, jauhnya jarak salah satu stasiun kerja dengan proses selanjutnya juga menjadi permasalahan yang terdapat pada Industri Mebel tersebut, serta banyaknya
WIP (Work In Process) yang ada pada setiap stasiun kerja.

Tujuan penelitian ini yaitu untuk merancang ulang tata letak fasilitas produksi Industri Mebel Bambu Karya Manunggal yang lebih efektif. Metode yang digunakan dalam penelitian ini adalah metode kualitatif ARC (Activity Relationship Chart). Metode kualitatif ini dipilih karena dalam metode ini menghubungkan aktivitas-aktivitas secara berpasangan sehingga semua aktivitas akan diketahui tingkat hubungan keterkaitan aliran (aliran material, peralatan, manusia, informasi dan lain-lain) serta keterkaitan proses [2]. dalam penelitian ini akan didukung dengan penggunaan software POM QM yang dapat digunakan untuk menghitung total jarak perpindahan sebuah permasalahan [3].

2. Metode Penelitian

Pada awalnya metodologi penelitian dimulai dengan melakukan identifikasi masalah dan pengumpulan data serta dilanjutkan dengan pengolahan data dengan tahapan sebagai berikut : [4] 
1. Perhitungan total jarak perpindahan dan OMH layout awal.

2. Perhitungan total jarak perpindahan dengan menggunakan software POM QM, jika hasilnya sama dengan perhitungan manual sebelumnya maka dilanjutkan dengan tahap selanjutnya.

3. Analisa kualitatif ARC

4. Perhitungan total jarak perpindahan dan OMH layout ARC.

5. Perhitungan total jarak perpindahan dengan menggunakan software POM QM, jika hasilnya sama dengan perhitungan manual sebelumnya maka dianjutkan dengan tahap selanjutnya.

6. Tahap pembahasan, tahap yang berisi pembahasan dari pengolahan data

7. Kesimpulan dan saran

\section{Hasil Dan Pembahasan}

Bambu sebagai salah satu komoditi perkebunan Indonesia memiliki potensi untuk ditingkatkan produksinya. Salah satu peningkatan dapat dilakukan dengan memperbaiki tata letak fasilitas produksi. Dari hasil perhitungan awal kondisi tata letak awal fasilitas produksi pada UKM didapatkan hasil total movement sebesar 941,45 .

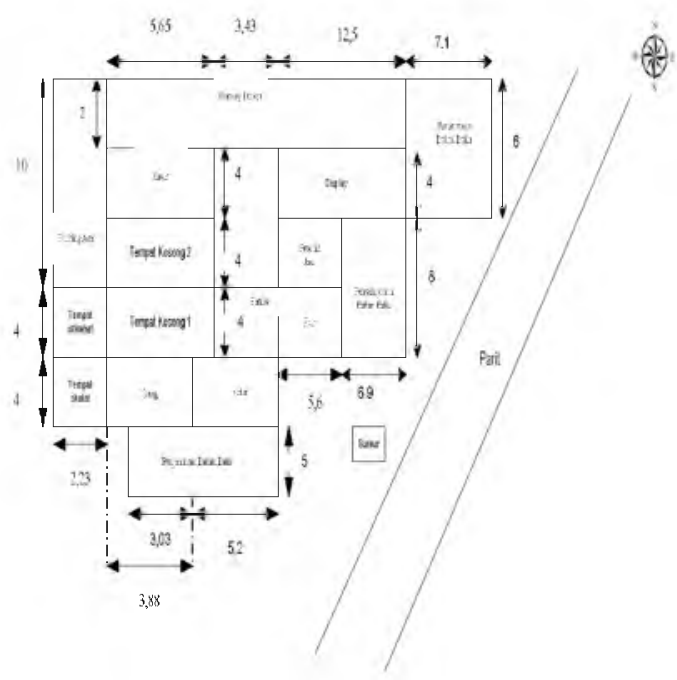

Gambar 1 Layout Awal

Tahap selanjutnya adalah dengan melakukan analisa kualitatif ARC, seperti pada Gambar 2. [5]

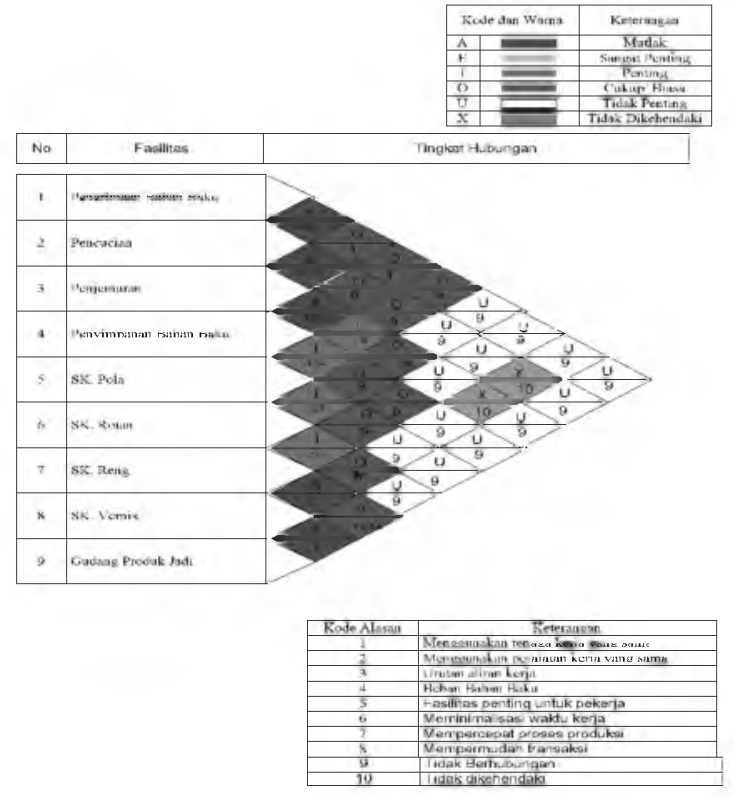

Gambar 2 Activity Relationship Chart

Setelah dilakukan analisis kualitatif dengan ARC, didapatkan layout bary dengan initial centroid seperti pada Tabel 1.

Tabel 1 Initial Centroid Layout ARC

\begin{tabular}{|c|c|c|c|c|}
\hline \multirow[b]{2}{*}{ Kode } & \multirow[b]{2}{*}{$\begin{array}{c}\text { Nama stasiun } \\
\text { kerja }\end{array}$} & \multicolumn{2}{|c|}{ Koordinat } & \multirow[b]{2}{*}{$\begin{array}{l}\text { Luas } \\
(\mathrm{m})\end{array}$} \\
\hline & & $\mathrm{x}$ & $\mathrm{y}$ & \\
\hline$A$ & $\begin{array}{l}\text { Penerimaan } \\
\text { Bahan Baku }\end{array}$ & 27,36 & 82,08 & 3 \\
\hline B & Pencucian & 34,735 & 130,26 & 3,75 \\
\hline $\mathrm{C}$ & $\begin{array}{l}\text { Penjemuran } \\
\text { Bahan Baku }\end{array}$ & 7,195 & 147,50 & 20,5 \\
\hline $\mathrm{D}$ & $\begin{array}{c}\text { Penyimpanan } \\
\text { Bahan Baku }\end{array}$ & 20,36 & 203,6 & 10 \\
\hline $\mathrm{E}$ & SK. Pola & 14,11 & 169,32 & 12 \\
\hline $\mathrm{F}$ & SK. Rotan & 8,71 & 139,36 & 16 \\
\hline $\mathrm{G}$ & SK. Reng & 4,17 & 66,72 & 16 \\
\hline $\mathrm{H}$ & Vernis & 5,055 & 60,66 & 12 \\
\hline $\mathrm{I}$ & Produk Jadi & 5,055 & 40,44 & 8 \\
\hline
\end{tabular}

Jarak rectilinear $=[\mathrm{Xi}-\mathrm{Xj}]+[\mathrm{Yi}-\mathrm{Yj}]$ $(\mathrm{A}-\mathrm{B})=[27,36-34,74]+[3-3,75]$ $=[7,38]+[0,75]=8,13$

Tabel 2 Total Jarak Material Handling Layout ARC

\begin{tabular}{l|l|l|l} 
SK & Jarak & Frekue & Jarak tempuh/hari
\end{tabular}




\begin{tabular}{|c|c|c|c|}
\hline $\begin{array}{c}\text { dari - } \\
\text { ke }\end{array}$ & $\begin{array}{c}\text { antar } \\
\text { stasiun } \\
\text { kerja }\end{array}$ & $\begin{array}{c}\text { nsi } \\
\text { pemin } \\
\text { dahan/ } \\
\text { hari }\end{array}$ & \\
\hline A-B & 8,13 & 20 & 162,6 \\
\hline B-C & 44,29 & 20 & 885,8 \\
\hline C-D & 23,66 & 20 & 473,2 \\
\hline D-E & 8,25 & 10 & 82,5 \\
\hline E-F & 9,4 & 10 & 94 \\
\hline F-G & 4,54 & 10 & 45,5 \\
\hline G-H & 4,885 & 10 & 48,85 \\
\hline H-I & 4 & 10 & 40 \\
\hline & Total & $1.832,35$ \\
\hline
\end{tabular}

Langkah selanjutnya adalah dengan melakukan perhitungan Ongkos Material Handling, hasil dari perhitungannya adalah sebagai berikut:

Penentuan ongkos material handling dari departemen A ke departemen B dengan menggunakan alat angkut manusia yaitu sebagai berikut:

1. Upah pekerja/ jam = upah tenaga kerja/hari jam kerja/hari

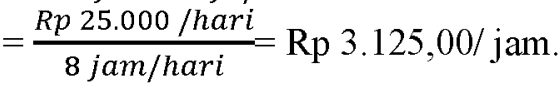

2. Jarak pengangkutan tiap jam $=$ Jarak tempuh tiap hari $\mathrm{x} \frac{1 \text { hari }}{\text { jam kerja/hari }}$

$=162,6 \times \frac{1 \text { hari }}{8 \text { jam } / \text { hari }}$

$=20,32 \mathrm{~m} / \mathrm{jam}$

3. Ongkos Material Handling $(\mathrm{OMH} / \mathrm{m})$ :

$\mathrm{OMH}$

Biaya peralatan+Biaya Operator+Biaya Perawatan (3)

$$
\begin{gathered}
\mathrm{OMH}=\frac{R p 3.125,00 / \mathrm{jam}}{20,32 / \mathrm{jam}} \\
=\mathrm{Rp} 154,47 / \mathrm{meter}
\end{gathered}
$$

4. Total ongkos material handling tiap hari $(\mathrm{OMH} /$ hari) untuk departemen $\mathrm{A}$ ke departemen $\mathrm{B}$ adalah :

Total OMH/ hari $=162,6 \mathrm{~m} /$ hari $\times \mathrm{Rp}$ $154,47 / \mathrm{m}=\operatorname{Rp} 25.116,8 /$ hari.

Hasil keseluruhan Ongkos Material Handling Layout ARC dapat dilihat pada Tabel 3.

Tabel 3. OMH Layout ARC

\begin{tabular}{|c|c|c|}
\hline \multicolumn{2}{|c|}{ Aliran proses } & \multirow{2}{*}{$\begin{array}{c}\text { OMH } \\
\text { (Rp) }\end{array}$} \\
\hline Dari & Ke & $25.116,8$ \\
\hline A & B & $24.997,3$ \\
\hline B & C & $24.999,1$ \\
\hline C & D & $25.029,7$ \\
\hline D & E & \\
\hline
\end{tabular}

\begin{tabular}{|c|c|c|}
\hline E & F & $24.994,6$ \\
\hline F & G & 24.988 \\
\hline G & H & $24.620,4$ \\
\hline H & I & 25.000 \\
\hline \multicolumn{2}{|c|}{ Total } & $199.745,9$ \\
\hline
\end{tabular}

Perhitungan total jarak material handling menggunakan software POM QM, diperoleh hasil 916,2

Sehingga didapatkan selisih jarak aliran material handling dan ongkos aliran material antara layout awal dengan layout hasil pengolahan pada ARC adalah sebesar: [6]

a. Selisih jarak aliran material

$=1.922,9-1.832,35=90,55$ meter , atau

$=(90,55 / 1.922,9) \times 100=4,94 \%$

b. Selisih ongkos material handling

$=\operatorname{Rp~200.135,6-Rp~199.745,9~}$

$=\operatorname{Rp} 389,9$, atau

$=(\operatorname{Rp~389,9-Rp~200.135,6)\times 100~}$

$=0,19 \%$

Maka dari perhitungan diatas didapat bahwa dengan menggunakan layout ARC akan mengurangi jarak perpindahan material sebesar 90,55 meter atau $4,94 \%$ dan mengurangi ongkos material handling sebesar Rp 389,9 atau sebesar $0,19 \%$.

Perbandingan total jarak perpindahan dan $\mathrm{OMH}$ layout awal dengan total jarak perpindahan dan $\mathrm{OMH}$ layout $\mathrm{ARC}$ dapat dilihat pada tabel 4 .

\begin{tabular}{|c|c|c|c|c|c|}
\hline \multicolumn{2}{|c|}{$\begin{array}{l}\text { Aliran } \\
\text { Proses }\end{array}$} & \multicolumn{2}{|c|}{$\begin{array}{c}\text { Hasil Layout } \\
\text { Awal }\end{array}$} & \multicolumn{2}{|c|}{$\begin{array}{c}\text { Hasil Layout } \\
\text { ARC }\end{array}$} \\
\hline Dari & $\mathrm{Ke}$ & $\begin{array}{l}\text { Jarak } \\
(\mathrm{m})\end{array}$ & $\begin{array}{l}\text { OMH } \\
\text { (Rp) }\end{array}$ & $\begin{array}{l}\text { Jarak } \\
(\mathrm{m})\end{array}$ & $\begin{array}{l}\mathrm{OMH} \\
(\mathrm{Rp})\end{array}$ \\
\hline $\mathrm{A}$ & $\mathrm{B}$ & 162,6 & $25.116,8$ & 162,6 & $25.116,8$ \\
\hline B & $\mathrm{C}$ & 885,8 & $24.997,3$ & 885,8 & $24.997,3$ \\
\hline $\mathrm{C}$ & $\mathrm{D}$ & 473,2 & $24.999,1$ & 473,2 & $24.999,1$ \\
\hline D & $\mathrm{E}$ & 82,5 & 24,981 & 82,5 & 24,981 \\
\hline $\mathrm{E}$ & $\mathrm{F}$ & 94 & $24.994,6$ & 94 & $24.994,6$ \\
\hline $\mathrm{F}$ & $\mathrm{G}$ & 45,5 & 24.988 & 45,5 & 24.988 \\
\hline $\mathrm{G}$ & $\mathrm{H}$ & 94,2 & $25.010,1$ & 48,85 & $24.620,4$ \\
\hline $\mathrm{H}$ & $\mathrm{I}$ & 85,2 & 25.000 & 40 & 25.000 \\
\hline Tc & & $1.922,9$ & $200.135,6$ & $1.832,35$ & $199.745,9$ \\
\hline
\end{tabular}

Tabel 4. Perbandingan Hasil Layout Awal
Rekomendasi perbaikan tata letak lantai produksi berdasarkan dari hasil ARC dapat dilihat pada Gambar 3. [7] 


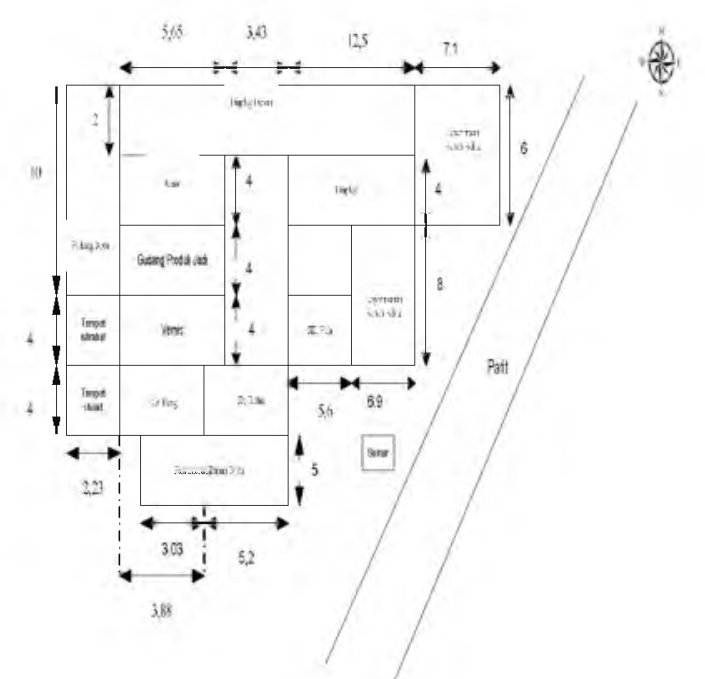

Gambar 3 Layout setelah ARC

4. Kesimpulan

Berdasarkan hasil penelitian yang telah penulis laksanakan pada Industri Mebel Bambu Karya Manunggal, dapat di tarik kesimpulan sebagai berikut:

1. Berdasarkan perhitungan layout awal di dapatkan total jarak perpindahan sebesar $1.922,9$ meter dengan ongkos material handling sebesar $\mathrm{Rp} 200.135,6$ dan setelah dilakukannya perhitungan berdasarkan ARC didapatkan total jarak perpindahan sebsar $1.832,35$ meter dengan ongkos material handling sebesar Rp 199.745,9.

2. Dari perhitungan layout awal dan layout usulan berdasarkan hasil pengolahan ARC di dapatkan bahwa terdapat selisih dari total jarak sebesar 90,55 meter atau sebsar 4,94 \% dan memiliki selisaih ongkos material handling sebesar $\mathrm{Rp}$ 389,7 atau sebsae $0,19 \%$.

\section{Saran}

Berdasarkan hasil penelitian yang telah dilakukan pada Industri Mebel Bambu Karya Manunggal Yogyakarta saran yang diberikan sebagai berikut :

1. Industri Mebel Bambu Karya Manunggal dapat menerapkan hasil penelitian ini untuk memperpendek jarak perpindahan material dan meminimumkan ongkos material handling yang ada.

2. Diharapkan kepada Industri Mebel Bambu Karya Manunggal Yogyakarta agar memperhatikan lingkungan tempat produksi seperti kebersihan, kerapian serta hal-hal yang lain yang mungkin bisa meningkatkan produkivitas pekerja

3. Diharapkan kepada Industri Mebel Bambu Karya Manunggal untuk mempertahankan serta meningkatkan kualitas produk.

4. Dengan masih terdapat banyaknya WIP (Work In Process) serta tata letak stasiun kerja yang dapat berubah sewaktuwaktu, disarankan untuk mengubah atau menerapkan budaya kerja sehingga dapat meningkatkan produktivitas Industri Mebel Bambu Karya Manunggal Yogyakarta. Penerapan budaya kerja dapat dijadikan bahan untuk penelitian selanjutnya dengan menyatukan $5 \mathrm{~S}$ dan tata letak fasilitas.

\section{DAFTAR PUSTAKA}

[1] Eko, P., Cahyono, B., N., 2014, Analisis Tata Letak Proyek Menggunakan Activity Relationship Chart dan MultiObjectives Function pada Proyek Pembangunan Apartemen De Papilio Surabaya, Jurnal Teknik POMITS, Vol 3, D131-D136.

[2] Abdillah Z, I., 2014. Perancangan Ulang Tata Letak Fasilitas Produksi dengan Menggunakan Metode Kualitatif (ARC) dan Algoritma CRAFT pada UD. Roti Bangkit Yogyakarta. Jurusan Teknik Industri, Sekolah Tinggi Teknologi Adisutjipto (STTA), Yogyakarta

[3] Ambika, S. 2013. Performance Enhancement in a Print Pack Firm by Layout Optimization. Departement of Printing Technology. Avinashilingan Institute For Home Science and Higher Education For Women, University, Coimbatore, Tamil Nadu, India.

[4] Apple, James, M., 1990, Tata Letak Pabrik dan Pemindahan Bahan, Edisi Ketiga, Terjemahan Nurhayati., Merdiono, ITB, Bandung.

[5] Hadiguna, R, ST., MT., Setiawan, H. ST., MT., Tata Letak Pabrik. Penerbit ANDI, Yogyakarta

[6] Harahap Sorimuda 2006, Perencanaan Pabrik, Penerbit GRAHA ILMU, Yogyakarta 
[7] Wignjosoebroto, S. 1996. Tata Letak

Pabrik dan Pemindahan Bahan.

Penerbit Guna Widya. Surabaya. 